\title{
FABRICATION CYCLES COMPARISON OF ASSEMBLIES AND MONOLITHIC PARTS MADE BY 3D PRINTING METHOD
}

\author{
Kinga Skrzek $^{1}$, Mariusz Piotr Hetmanczyk ${ }^{2}$ \\ ${ }^{1}$ Future Industry Platform, Jacka Malczewskiego 24 St., 26-609, Radom, Poland \\ ${ }^{2}$ The Silesian University of Technology, Faculty of Mechanical Engineering, \\ Konarskiego 18A St., 44-100, Gliwice, Poland
}

Corresponding author: Mariusz Piotr Hetmanczyk, mariusz.hetmanczyk@polsl.pl

\begin{abstract}
The article presents an analysis of the timeconsuming, energy-consuming, and cost-consuming nature of 3D printing a three-dimensional polymer components made in two separate approaches: assembly and monolith structure of various materials (automatic filament change required). The introduction includes the definition of $3 \mathrm{D}$ printing, its advantages and examples of practical applications, as well as the reason for undertaking the researches described in the article. The justification of the form of 3D sample models was discussed in detail, as well as the methodology adopted by the authors for comparing the print characteristics and the steps of the printing cycles (print preparation, the course of the printing process and post-processing). A comparison of the materials consumption in the phasess of manual and automatic filament change in the mixer were also described. The test printout was made on the Prusa i3 MK3S printer for filament deposition (FDM or FFF methods). For automatic filament mixing, the Palette 2 Pro device was used. The conclusions also include guidelines for the design and production of models made in one continuous printing cycle (using automatic filament feeding devices). Monolithic elements are less accurate, while elements with replaceable filaments are cheaper, less energy-consuming and the material consumption is lower.
\end{abstract}

Key words: $3 \mathrm{~d}$ printing, optimization, reduction of postprocessing activities, material, filament

\section{INTRODUCTION}

$3 \mathrm{D}$ printing is a production process in which threedimensional objects are created, most often used in rapid prototyping [1-3]. The advantage of 3D printing is the ability to create physical models of objects using layers of different materials to create a complete threedimensional object [4-7]. 3D printing has found many applications in production applications (including mass minimization, fast production, rapid prototyping, production and testing of prototypes and agile instrumentation), medical applications (bio-printing, making prototypes and medical devices, printing pills), industrial (printing of clothes, production of works of art and jewellery on an industrial scale, applications in the automotive industry, construction, development of prototypes and parts of firearms, production of parts and components of computers and robots, prefabrication of sensors and actuators, applications dedicated to space and aviation and sociocultural (art and jewellery production, communication techniques, home printing, education and research, environmental protection, cultural heritage, printing from special materials) [8-10].

The unquestionable advantage of the $3 \mathrm{D}$ printing is the ability to manufacture monolithic components with complex shapes (without the need to make multi-element assemblies), use many variants of construction materials colours and permanently combine certain groups of materials (with similar physicochemical properties) $[11,12]$.

In the initial phase of using additive methods, the components were printed only as three-dimensional monolithic structures (from one type of material). If it was necessary to make an assembly, the printed parts were joined using detachable (shaped, less often threaded or drilling) or non-detachable (e.g. gluing) connections. Due to the possible print parameters (including the accuracy of reproducing dimensions and shapes, roughness, flatness and parallelism of surfaces, deviations of the axis (in case of cylindrical components), the elements require a lot of time spent on processing and adjusting the mating surfaces [13]. At the current stage of $3 \mathrm{D}$ printing development, fabrication of monolithic parts is not a challenge. There are dedicated mixer solutions on the market that allow to automatically change the filament without interrupting the printing process [14]. The disadvantage of such solutions is the relatively long time of changing the filament and the large volume of waste generated at the stage of changing the material [15]. The unquestionable advantage, however, is the 
elimination of the assembly, which also reduces the number of steps in the production process and minimizes the total time of manufacturing the element [16]. The article compares the values of 3D printing parameters (time-consuming, energyconsuming and total cost) for the production of a printed element with and without automatic filament change (printing of assembly components) $[17,18]$.

\section{DEVELOPMENT OF TEST SAMPLES}

In terms of the tests, two different approaches were considered:

- monolith of various materials (automatic filament change required; P1 type) - made during one printing cycle (without change of the filament, a nozzle and other manual activities during printing),

- assembly of components (P2, P3 types) - made of several parts made by 3D printing, while using well-known methodologies (Lean management, SMED, Poka Yoke - used to minimize the number of assembly errors and shortening the assembly time):

- P2 - components of the assembly printed in two cycles (without the use of the Palette 2 Pro mixer),

- P3 - assembly components printed in one cycle (using the Palette 2 Pro mixer).

The adopted 3D model is a prism measuring 40x40×24 millimetres. The concept of the modelled elements (tested samples) is presented in Figure 1.

a)

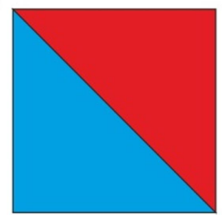

b)

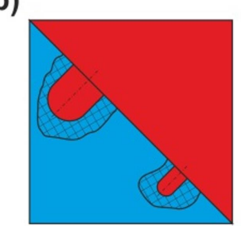

c)

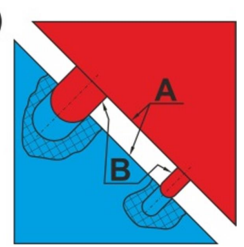

Fig. 1. Diagram of samples used for tests: a) monolithic (made in one cycle, with automatic filament change), b) composed of two elements, c) assembly method; where:

A, B - surfaces requiring treatment before assembly

In the first case (Figure 1(a)), a mixer (Palette 2 Pro by Mosaic Manufacturing) was used for automatic filament change, and the printout was made during one working cycle. In this way, a monolith with a variable colour of the geometric structure was obtained.

In the second of the analysed cases, two separate approaches were used:

- printing of two components with the use of a colour mixer (P2) - elements placed on the table made in one cycle with automatic filament change,

- printing of two components in two separate cycles (P3).

In order to prepare the samples, 3D models (Figure 2) were made in CAD software (Inventor Professional
2017).

The adopted constructional form of 3D models (Figure 2) allows for a quick verification of the assumptions, with a simultaneous elimination of an influence of factors disturbing the research subject (e.g. the influence of supports on the printing time and the generation of waste, which are strongly dependent on the complexity of the printed model) [19-21].

a)

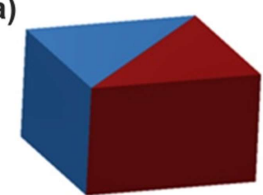

b)

Fig. 2 Solid models of manufactured parts: a) monolith,

b) assembly

The basic parameters used to determine the profitability of making a part using 3D printing include cost, energy and time. In connection with the established evaluation criteria, the following activities were distinguished in the process of making the element using 3D printing (Table 1).

Table 1. List of activities in the process of making a finished component ( $\mathrm{x}$ - activity necessary to be performed in the process)

\begin{tabular}{|c|c|c|c|c|}
\hline Step & Action & P1 & $\mathrm{P} 2$ & $\mathrm{P} 3$ \\
\hline 1 & Preparation of the 3D model & \multicolumn{3}{|c|}{$\mathrm{x}$} \\
\hline 2 & Generating GCODE & \multicolumn{3}{|c|}{$\mathrm{x}$} \\
\hline 3 & $\begin{array}{c}\text { Preparation and calibration } \\
\text { of the Palette } 2 \text { Pro }\end{array}$ & $\mathrm{x}$ & & $\mathrm{x}$ \\
\hline 4 & $\begin{array}{l}\text { Preparation and calibration } \\
\text { of the Prusa i3 MK3S printer }\end{array}$ & \multicolumn{3}{|c|}{$\mathrm{x}$} \\
\hline 5 & Printing process & $\mathrm{x}$ & $\mathrm{x}$ & $\mathrm{x}$ \\
\hline 6 & $\begin{array}{l}\text { Removing the element from } \\
\text { the 3D printer table }\end{array}$ & \multicolumn{3}{|c|}{$\mathrm{X}$} \\
\hline 7 & Filament replacement & & $\mathrm{x}$ & \\
\hline 8 & Cleaning the table & \multicolumn{3}{|c|}{$\mathrm{x}$} \\
\hline 9 & $\begin{array}{l}\text { Post-processing of mating } \\
\text { surfaces (mechanical } \\
\text { processing with hand tools) }\end{array}$ & & $\mathrm{X}$ & $\mathrm{x}$ \\
\hline 10 & Assembly & & $\mathrm{x}$ & $\mathrm{x}$ \\
\hline
\end{tabular}

The stages of preparation of the 3D model, postprocessing and assembly were excluded from the scope of the parameter comparison due to the strong dependence on the degree of complexity of the printed component or variable assembly complexity. However, they were indicated as steps necessary to make a fully functional assembly. The main focus is the print cycle, especially the automation of filament replacement.

\section{MATERIALS AND METHODS}

In order to determine the parameters influencing the $3 \mathrm{D}$ printing process, tests were carried out on the test stand shown in Figure 3. The stand consists of: 
- the Prusa i3 MK3S printer for filament deposition (FDM or FFF methods),

- an automatic filament mixer, the Palette 2 Pro device enabling the use of four different filaments while the 3D printer nozzle remains unchanged.

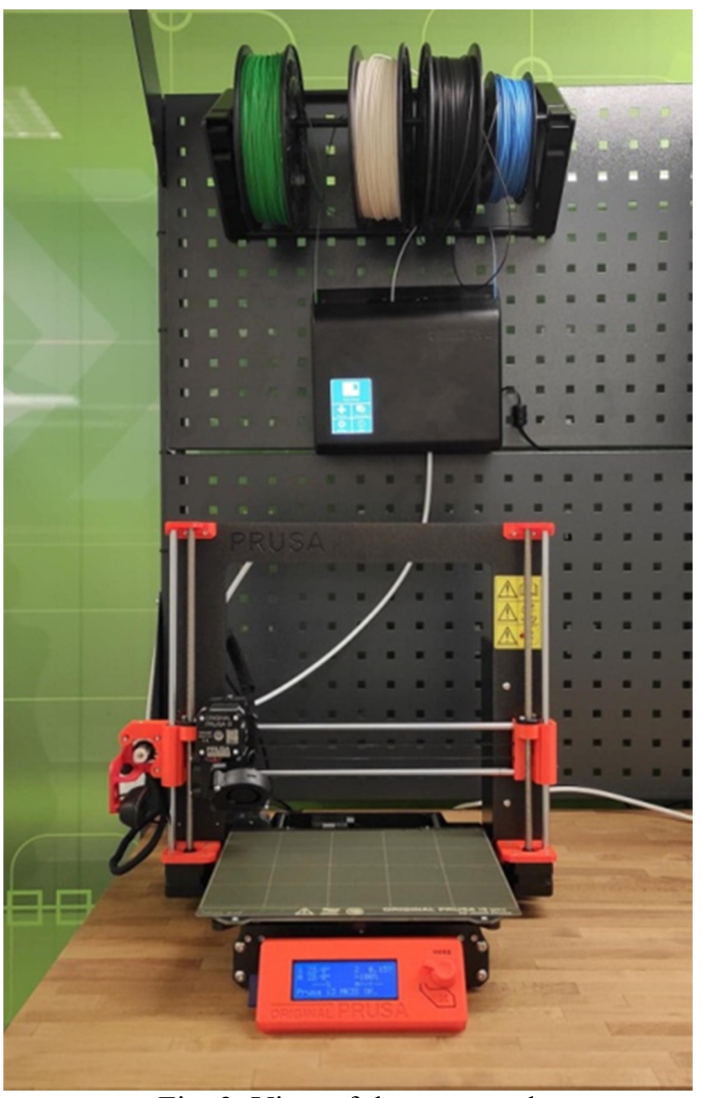

Fig. 3. View of the test stand

The UltraPLA filament (Noctuo) with a variable colours was used for the research.

The next step, after modelling the samples, was to prepare the model for the $3 \mathrm{D}$ printing process (selection of the appropriate file format, appropriate scaling, division into components to minimize the number of supports, selection of print parameters) $[22,23]$. The prepared files (in g-code format) were configured with the same parameter values (Table 1) for all considered cases.

Table 2. Basic parameters of printed parts according to the manufacturer's recommendations

\begin{tabular}{|c|c|c|}
\hline Parameter & Value & Unit \\
\hline The percentage of filling & 15 & $\%$ \\
\hline Table temperature & 60 & \multirow{2}{*}{${ }^{\circ} \mathrm{C}$} \\
\hline Head temperature & 210 & $\mathrm{~mm} / \mathrm{s}$ \\
\hline Stroke print speed & 45 & $\mathrm{~mm} / \mathrm{s}$ \\
\hline Fill printing speed & 80 & $\mathrm{~mm}$ \\
\hline Layer height & 0.15 & $\mathrm{~mm}$ \\
\hline The height of the first layer & 0.20 & \\
\hline
\end{tabular}

Prepared configuration files were uploaded to memory and printer, test prints were made (in the provided variants). In the $\mathrm{P} 1$ and $\mathrm{P} 3$ variants, additional waste were created due to the automatic filament change (Figure 4).

In the case of an object consisting of parts, the surface after printing was machined (external surfaces of pins and contact surfaces, Figure 1(c)) due to adjusting the dimensions of the elements required for proper assembly.

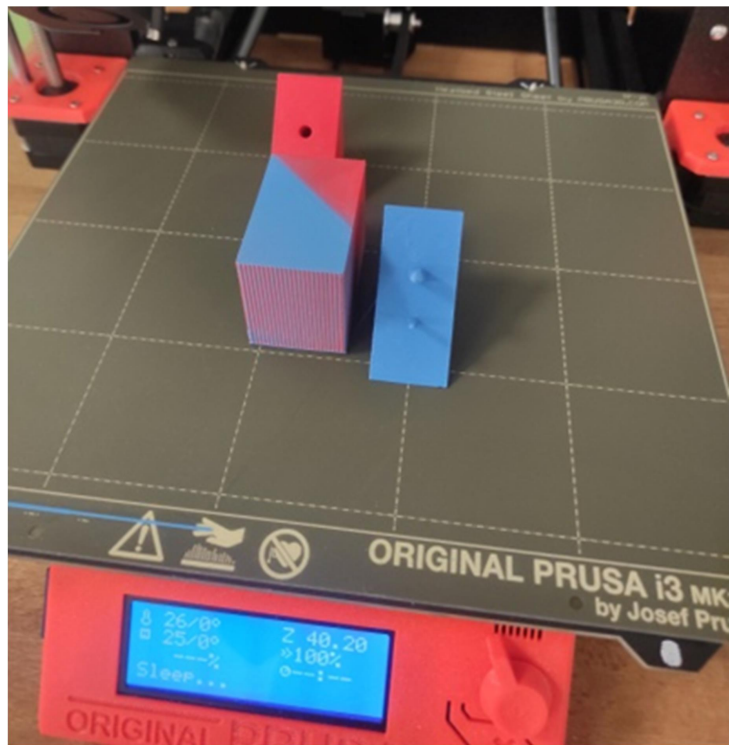

Fig. 4. View of the printer table after the completed 3D printing process using the Palette 2 Pro mixer

As regards post-production activities, the stage of external surface treatment of printed elements was omitted. The effect of manual finishing is presented in Figure 5(a). a)

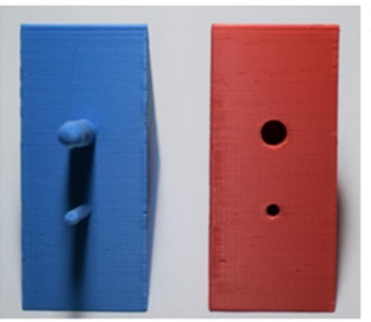

Fig. 5. View: a) parts after manual finishing, b) assembly

of components b)

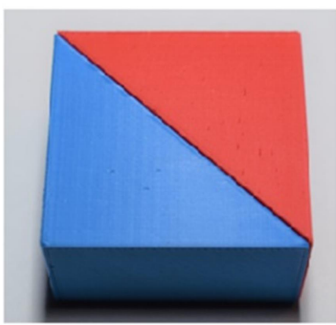

After processing, the elements were assembled (Figure 5(b)). In order to eliminate assembly errors, the variability of the geometrical dimensions of the pins was used in accordance with the Poka-Yoke methodology, which enables the assembly to be performed in one possible way [24-27]. The assembly shows a slight shift of the side surfaces of the assembly components (Figure 5(b)), which is due to the inaccuracy of the method.

The description of the P1 type element has been omitted due to the simplicity of the course of action and the significant similarity to the presented variant. 


\section{RESULTS AND DISSCUSIONS}

In the field of research, the following process parameters were analysed:

- total printing time of elements - defined as the time counted from the moment of starting the $3 \mathrm{D}$ printer until the end of the printing process (in the case of assembled type, the sum of the times of execution of two components was assumed),

- total material consumption - in the scope of one printing cycle (in the case of assembly, the sum of the production times of two components was assumed),

- energy consumption - resulting from the operation of the test stand,

- time-consuming - covering all activities indicated in Table 1 (excluding the time required for model preparation, postprocessing and assembly).

In the case of P2, P3 variants the values of the total printing time and the total material consumption were taken as the sum of the execution times of all components of the assembly.

Figure 6 shows a comparison of the times of individual activities (Table 1) in relation to the three analysed variants $\mathrm{P} 1, \mathrm{P} 2$ and $\mathrm{P} 3$.

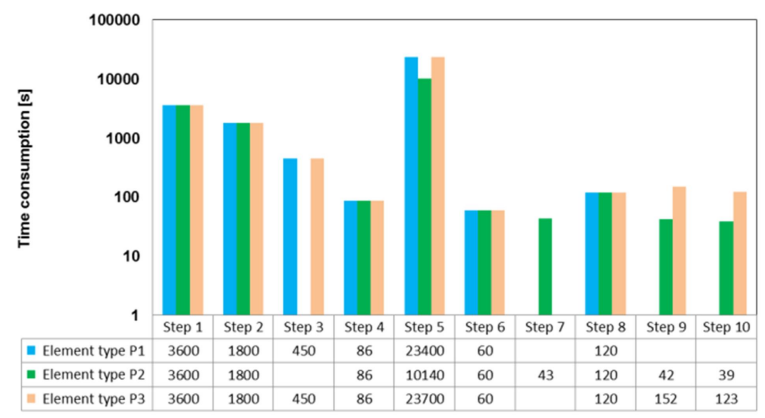

Fig. 6. Time-consumption diagram (numbering of activities in accordance with Table 1)

The values of the preparation and calibration times of the test stand in both cases assume similar values. However, the time-consuming process of 3D printing with the use of a mixer is much greater.

This condition results from the necessity to clean the nozzle of filament, and to make a waste.

Parts made with the use of the Palette 2 Pro device additionally require longer machining due to the lower precision of the dimensional values (in particular the diameter of the connecting pins) related to the mixing process and the use of other software (Slicer) to generate the GCODE [28- 31].

Consecutively, the material consumption was determined during one printing cycle (Figure 7).

The analysis shows that the printing of elements with the use of the device requires the use of more material
$(33.3 \mathrm{~m})$ than using only a 3D printer $(6.09 \mathrm{~m})$.

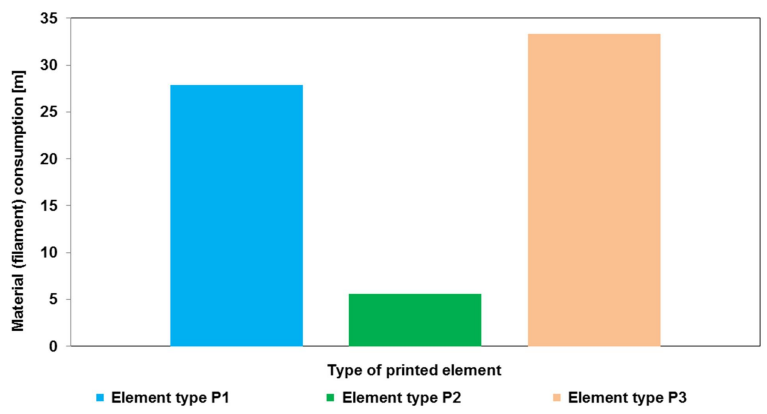

Fig. 7. Material consumption chart

The reason for this is the automatic replacement of the filament, resulting in the formation of a large amount of waste (Figure 4).

The conducted research also allowed to determine the energy consumption of the production cycles of individual elements, Figure 8).

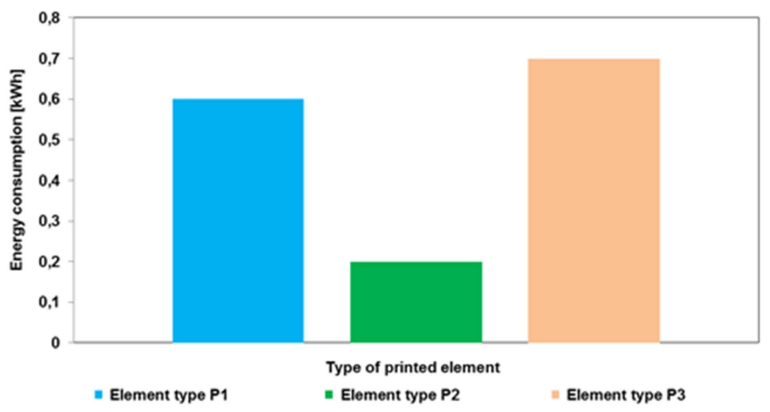

Fig. 8. Graph of energy consumption

The cost of the material of printing a spatial detail made of plastic made in two separate approaches, assuming the cost of:

- filament (Table 3),

- electricity of the printer (assembly of P2 type), printer and mixer (P1, P3 types).

Table 3. Costs of the material used

\begin{tabular}{|c|c|c|c|}
\hline \multirow{2}{*}{ Name of the element } & P1 & P2 & P3 \\
\cline { 2 - 4 } & \multicolumn{3}{|c|}{ Cost [EUR] } \\
\hline $\begin{array}{c}\text { Printout of a monolithic } \\
\text { element }\end{array}$ & 0.55 & - & - \\
\hline Element with holes & - & 0.26 & 0.26 \\
\hline Element with protrusions & - & 0.29 & 0.29 \\
\hline Waste from a 3D printer & - & 0.03 & - \\
\hline Waste from Palette 2 Pro & 2.09 & - & 2.44 \\
\hline Sum: & 2.64 & 0.58 & 2.99 \\
\hline
\end{tabular}

Table 4 shows the costs of electricity for the components of the configured test stand. P3 is the most expensive to produce. It costs 0.12 [eur]. The cheapest is $\mathrm{P} 2$. The cost of production of this element is 0.02 [eur].

Additionally, the mass of the printed elements was measured in order to compare the material consumption more precisely. 
Table. 4. Costs of electricity consumption

\begin{tabular}{|c|c|c|c|}
\hline \multirow{2}{*}{ Name of the element } & P1 & P2 & P3 \\
\cline { 2 - 4 } & \multicolumn{3}{|c|}{ Cost [EUR] } \\
\hline Prusa i3 MK3S printer & 0.01 & 0.02 & 0.06 \\
\hline Palette 2 Pro device & 0.04 & - & 0.06 \\
\hline Sum: & 0.05 & 0.02 & 0.12 \\
\hline
\end{tabular}

The measurement results are presented in Table 5.

Table 5. The weight of individual items or the assembly

\begin{tabular}{|c|c|c|c|}
\hline \multirow{2}{*}{ Name of the element } & P1 & P2 & P3 \\
\cline { 2 - 4 } & \multicolumn{3}{|c|}{ Weight [g] } \\
\hline $\begin{array}{c}\text { Print out of a monolithic } \\
\text { element }\end{array}$ & 18 & - & - \\
\hline Element with holes & - & 9 & 9 \\
\hline Element with protrusions & - & 10 & 10 \\
\hline Waste from a 3D printer & - & 1 & - \\
\hline Waste from Palette 2 Pro & 64 & - & 83 \\
\hline Sum: & 82 & 20 & 102 \\
\hline
\end{tabular}

The analysis of the parameters listed in Table 5 shows that:

- the part made of monolith is lighter than those made in separate parts,

- the largest waste is generated with the P3 trial, which generates an additional cost.

Another solution is to make a series of items using the Palette 2 Pro. The advantage of this solution is a better possibility of planning the production process (Figure 9). The production price of one item is also reduced. The basic limitation, however, is the overall dimensions of the table, which determine the maximum number of elements produced in one cycle.

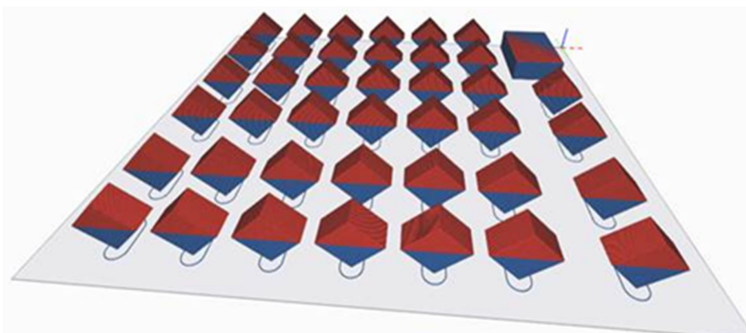

Fig. 9. Slicer menu showing the production of a series of 40 monolithic parts (the P1 type)

It is worth mentioning that in the case of the P1 type element, a different orientation (Figure 9) of the model was used than in the case of the P3 element printout. The proposed setting reduced the volume of waste, but the volume is still not acceptable from an economic point of view.

\section{CONCLUSIONS}

An element made in the form of a monolith (during one cycle) is characterized by a lower accuracy of the printout. This is due to the Slicer used and the material (filament) replacement process. The cost, energy, time and material consumption in the case of printing cycles with automatic filament replacement are greater than in the case of making elements with the use of a 3D printer alone [32].

At this stage of the research, it can be concluded that the printout with automatic filament change has the following advantages:

- minimization of design activities when making a 3D model, as there is no need to design connections,

- elimination of the time of pre-processing activities (uploading the model, setting printer parameters, calibration, etc., in relation to individual components of the assembly),

- elimination of assembly activities, and thus the post-processing of fastener elements,

- avoidance of dimensional inaccuracies caused by assembly.

The biggest disadvantage of prints with automatic filament change is the volume of waste (and thus the cost and time) of the printout. In the case of the existing configuration of the station, there is no possibility of a significant reduction the waste generated during the $3 \mathrm{D}$ printing process $[33,34]$.

The next planned research step is to check the impact of the printing parameters settings (i.e. the percentage and shape of the filling, the degree of geometry complexity and the material used) and the dimensions of the printed element on the volume of waste.

The process of $3 \mathrm{D}$ printing by making parts with the help of a device for making multi-colour elements always produces waste. Exist possibility of minimal impact on the amount of the waste by arranging the printed element in an optimal way. The P3 element is the most material-consuming to manufacture. This parameter results from the generated waste. The cheapest material is $\mathrm{P} 2$, because there is no waste in these elements. The same is true for $3 \mathrm{D}$ printing time. Research on this issue should be continued.

Further research should be continued using other materials and the geometry of the sample. The execution of elements with complex geometry using four filaments at the same time should be also tested.

\section{REFERENCES}

1. Shafiee A., Atala A. (2016). Printing technologies for medical applications, Trends in Molecular Medicine, 3, 254-265.

2. Goole J., Amighi K. (2016). $3 D$ printing in pharmaceutics: A new tool for designing customized drug delivery systems, International Journal of Pharmaceutics, 499, 376-394.

3. Sieminski P., Budzik G. (2014). Additive techniques. 3D Printers, Publishing House of the Warsaw University of Technology (Warsaw).

4. Mandrycky C., Wang Z., Kimb K., Kima D-H. 
(2016). 3D bioprinting for engineering complex tissues, Biotechnoly Adv, 34(4), 422-434.

5. Ozbolat I.T., Yu Y. (2013). Bioprinting toward organ fabrication: challenges and future trends. IEEE Transactions on Biomedical Engineering, 60(3), 691-699.

6. Kordowska M., Choromańska M., Musiał W., Plichta J. (2015) $3 D$ printing in the automotive industry, Coaches, 16(6), 123-128.

7. Plichta J., Plichta S. (1999). Computer Integrated Manufacturing, University Publishing House of Koszalin University of Technology (Koszalin).

8. Konopacki J. (2012). The usefulness of consumer $3 D$ printers in FDM technology for creating architectural models, Space and form, 18, pp. 65-80.

9. Zhang F., Tuck C., Hague R., He Y., Saleh E. Li Y., Sturgess C., Wildman R. (2016). Inkjet printing of polyimide insulators for the $3 D$ printing of dielectric materials for microelectronic applications. Journal of Applied Polymer Science. 133(18).

10.Carlson A., Bowen A.M., Huang Y., Nuzzo R.G., Rogers J.A. (2012). Transfer printing techniques for materials assembly and micro/nanodevice fabrication, Advanced Materials, 24(2012), 5284- 5318.

11. Burleson S., Baker J., Ting Hsia A., Xu Z. (2015) Use of $3 D$ printers to create a patient-specific $3 D$ bolus for external beam therapy. Journal of Applied Clinical Medical Physics, 16(3), 166-178.

12. Murphy S., Atala A. (2014) $3 D$ bioprinting of tissues and organs. Nature Biotech, 32(773), 773-785

13. Muzalewska M., Szczodry B., SamolczykWanyura D., Wyleżoł M. (2014). Computer aided and generative technologies in planning the reconstruction of the facial part of the skull, Engineering Modeling, 52, 147-153.

14. Kromka-Szydek M., Wrona M., JędrusikPawłowska M. (2013). Strength analysis of the Unilock 2.4 system used in maxillofacial surgery, Engineering Modeling, 47, 111-122.

15. Richard van Noort. (2012): The future of dental devices is digital, Dental Materials, 28(2012), 3-12.

16. Wendeker M., Pietrykowski K., Magryta P.: (2011). Designing a Wankel injector adapter using the rapid prototyping method. Advances in science and technology, 7, 214- 218.

17. Zenou M., Kotler Z. (2016). Printing of metallic $3 D$ micro-objects by laser induced forward transfer. Optical Society of America, 24(2), 1431-1446.

18. Lukic' M., Clarke J., Tuck C., Whittow W., Wells G. (2016): Printability of elastomer latex for additive manufacturing or $3 D$ printing. Journal of Applied Polymer Science, 133(4), 133-140.

19. Kowalewski J., Całka R. (2010) The usefulness of the 3DP method of rapid prototyping in the process of adapting small arms to firing simulated shots. Military Institute of Armament Technology, R. 39, z. 113, 53-62

20. Dudek P. (2013). FDM 3D printing technology in manufacturing composite elements, Archives of Metallurgy and Materials, 58, 1415-1418.

21. Fastermann P. (2012). 3D-Druck/Rapid Prototyping, Springer-Verlag Gmbh (Berlin).

22. Chua C; Leong K., Lim C. (2003). Rapid Prototyping, World Scientific, 124-130.

23. Czerwiński K., Czerwiński M. (2013). 3D printing, InfoAudit (Warsow).

24. Freedman D. (2013). Layer By Layer. Technology Review. Academic Search Premier, 50-53 25. Hopkinson, N \& Dickens, P. (2006). Emerging Rapid Manufacturing Processe', in Rapid Manufacturing; An industrial revolution for the digital age, Wiley \& Sons Ltd, (Chichester).

26. Kißling W., Renner R., Zaunseder B. (2000). Rapid Prototyping, VDE Verlag Gmbh (Berlin).

27. Kamrani A. Nasr A. (2010). Engineering Design and Rapid Prototyping. Springer-Verlag Gmbh, 3-22

28. Wyleżoł M. Mazulewska M. (2015). Modeling methodology in biomedical engineering with the use of reconstructive engineering. Mechanic. $\mathrm{Nr}$ 2, 1-12.

29. (2015): dysk optyczny $\mathrm{nr} 42$, s. $1 \div 12$.Pearce, Joshua M.; et al. (2010). 3-D Printing of Open Source Appropriate Technologies for Self-Directed Sustainable Development, Journal of Sustainable Development, 3(4), 17-29.

30. Symes, M. D.; Kitson, P. J.; Yan, J.; Richmond, C. J.; Cooper, G. J. T.; Bowman, R. W.; Vilbrandt, T.; Cronin, L. (2012). Integrated 3D-printed reactionware for chemical synthesis and analysis. Nature Chemistry, 4, 349-354.

31. Wittbrodt, B. T.; Glover, A. G.; Laureto, J.; Anzalone, G. C.; Oppliger, D.; Irwin, J. L.; Pearce, J. M. (2013). Life-cycle economic analysis of distributed manufacturing with open-source 3-D printers. Mechatronics, 23, 713-726.

32. Mazgajczyk E., Szymczyk P., Chlebus E. (2014). The use of rep-rap technology for the production of functional structures from PLA, Current Problems of Biomechanics, 8, 109-114.

33. Mazgajczyk E., Szymczyk-Ziółkowska P., Chlebus E. (2014). The use of the REP-RAP technology for the production of functional structures from PLA. Current Problems of Biomechanics, 2(8), 109-114.

34. Bębenek K., Błaszczyk A., Kiryk J., Kotowski D., Kowalska K.,, Szczygielski T., Mazgajczyk E., Szymczyk-Ziółkowska P., Badora G., Bryła E., Dobrzyński M., Rybak Z. (2016). Application of $C A D / C A M$ technology in restorative dentistry literature review. Medical Engineer and Physicist, 5(2), 99-104.

Received: April 28, 2021 / Accepted: December 20, 2021 / Paper available online: December 25, 2021 (C) International Journal of Modern Manufacturing Technologies 